\title{
The appraisal of facial beauty is rapid but not mandatory
}

\author{
Annekathrin Schacht, Kaitja Werheid, And Werner Sommer \\ Humboldt University at Berlin, Berlin, Germany
}

\begin{abstract}
Facial attractiveness is an important source of social affective information. Here, we studied the time course and task dependence of evaluating attractive faces from a viewer's perspective. Event-related brain potentials (ERPs) were recorded while participants classified color portraits of unfamiliar persons according to gender and facial attractiveness. During attractiveness classification, enhanced ERP amplitudes for attractive and nonattractive faces relative to faces of intermediate attractiveness were found for an early component around $150 \mathrm{msec}$ and for the late positive complex (LPC). Whereas LPC enhancement conforms to previous studies employing various types of affective stimuli, the finding of an early effect extends earlier research on rapid emotion processing to the dimension of facial attractiveness. Dipole source localization of this early ERP effect revealed a scalp distribution suggesting activation of posterior extrastriate areas. Importantly, attractiveness-related modulations of brain responses were only marginal during the gender decision task, arguing against the automaticity of attractiveness appraisal.
\end{abstract}

Facial attractiveness is considered a key feature in social interactions, and one that plays a major role in peer and mate choice (Etcoff, 1999). Consequently, a large body of research has focused on the physical characteristics that render a face attractive. Some major factors that have been suggested are the averageness of a face (Langlois \& Roggman, 1990; Rhodes \& Tremewan, 1996), its symmetry (Rhodes, Proffitt, Grady, \& Sumich, 1998; but see Zaidel \& Deblieck, 2007) and familiarity (see, e.g., Peskin \& Newell, 2004; Rhodes \& Tremewan, 1996), and hormone-dependent facial features (see Thornhill \& Gangestad, 1999, for a review). However, research has only recently begun to investigate the neuronal processes underlying the appraisal of facial attractiveness in the mind of the beholder.

Neuroimaging studies have reported several brain areas that are differentially responsive to attractive and nonattractive faces. Typically, reward- and emotion-related areas - such as the orbitofrontal cortex, basal ganglia, and amygdala - have been shown to be activated by facial attractiveness (Aharon et al., 2001; Kampe, Frith, Dolan, \& Frith, 2001; Kranz \& Ishai, 2006; Nakamura et al., 1998; O'Doherty et al., 2003; Winston, O'Doherty, Kilner, Perrett, \& Dolan, 2007). These effects may be related to the aesthetic aspects of facial beauty, because they are independent of the gender of the viewers or of the persons depicted. In addition, a component of attractiveness due to sexual attraction or reproductive fitness has been suggested (see, e.g., Senior, 2003) that is sensitive to gender or sexual orientation. Across different imaging studies, the brain areas specifically responding to the facial attrac- tiveness of potential mates are quite diverse, ranging from the superior temporal sulcus (O'Doherty et al., 2003) to the basal ganglia (specifically, nucleus accumbens; Aharon et al., 2001) to the medial orbitofrontal cortex (OFC; Kranz \& Ishai, 2006). Interestingly, recent findings have demonstrated enhanced OFC activation to faces of potential partners, including same-sex mates in homosexual participants, which it has been suggested reflects the higher reward value of these faces, irrespective of their reproductive fitness (Ishai, 2007).

Although everyday experience suggests that the appraisal of attractiveness is a fairly rapid process, only a few objective data have been collected on this issue. A recent masking study by Olson and Marshuetz (2005) showed that attractiveness is perceived even if faces are exposed for only a very short time, suggesting that attractiveness is assessed rapidly and on the basis of minimal visual information. More direct evidence on the time course and locus of action of attractiveness may be gained from event-related brain potentials (ERPs). The few pertinent ERP studies have indicated two subsequent intervals during which attractiveness modulates brain processes. The most robust finding is a modulation of the so-called late positive complex (LPC). Johnston and coworkers conducted two studies involving the presentation of facial portraits that varied in specific attractiveness-related features (e.g., chin length; Johnston \& Oliver-Rodríguez, 1997; Oliver-Rodríguez, Guan, \& Johnston, 1999). Faces rated as attractive elicited larger LPC amplitudes at parietal and central electrodes between 400 and $600 \mathrm{msec}$ after target onset. This finding is in line with other reports of LPC increases for various types of

A. Schacht, schachta@hu-berlin.de 
emotional stimuli, including affectively connotated words (Fischler \& Bradley, 2006; Schacht \& Sommer, 2008), scenic pictures (Cuthbert, Schupp, Bradley, Birbaumer, \& Lang, 2000; Schupp, Junghöfer, Weike, \& Hamm, 2004), and faces with emotional expressions (e.g., Schupp, Öhman, et al., 2004; Schutter, de Haan, \& van Honk, 2004; Werheid, Alpay, Jentzsch, \& Sommer, 2005).

Recently, we investigated ERP correlates of appraising facial attractiveness by comparing attractive and less attractive faces that were preceded by various types of primes (Werheid, Schacht, \& Sommer, 2007). In line with the above-mentioned literature, we found larger LPC amplitudes to attractive than to less attractive faces, but also an earlier effect around $250 \mathrm{msec}$, consisting of an enhanced right-occipital negativity and left-frontal positivity for attractive faces relative to less attractive faces. Both ERP effects occurred independently of whether the actual stimuli corresponded with the primes. Although these findings were the first to demonstrate attractivenessrelated ERP effects prior to the LPC, they were in line with several previous studies on emotional face processing that had also revealed ERP effects prior to the LPC. For example, threatening facial expressions compared with neutral ones evoked posterior negativities at similar latencies between 200 and $320 \mathrm{msec}$ after stimulus presentation (Balconi \& Pozzoli, 2003; Schupp, Öhman, et al., 2004; Schutter et al., 2004). Öhman and Mineka (2001) interpreted these findings as the facilitation of automatic processing of fear-inducing stimuli by a "fear system" that enables rapid flight reactions, and thereby subserves survival. In a recent study, we found an enhanced negativity at posterior electrode sites to happy as compared with neutral faces at around $170 \mathrm{msec}$ (Schacht \& Sommer, 2008). Importantly, this early effect showed a scalp distribution not corresponding to the N170, but instead similar to that found in affective picture processing (see, e.g., Schupp, Junghöfer, Weike, \& Hamm, 2003a, 2003b, 2004; Schupp et al., 2007) - that is, the early posterior negativity (EPN; see, e.g., Schupp et al., 2003a, 2003b) that has been related to spontaneous attention capture by emotionally salient stimuli (e.g., Schupp et al., 2007). Complementary evidence comes from a study by Eimer, Holmes, and McGlone (2003), who reported a facial expression effect during the N170 time range but with a scalp distribution that differed from the N170. Interestingly, this effect appeared only when attention was allocated to emotional expression, indicating a strong task dependency of this effect.

Whereas the studies above focused on emotional facial expressions, several findings have indicated that facial attractiveness is also appraised relatively quickly. First, the above-mentioned study by Johnston and Oliver-Rodríguez (1997, Figure 5) appeared to show an early effect around $250 \mathrm{msec}$ for attractiveness, which unfortunately was not analyzed. Second, two further studies revealed even earlier ERP modulations, possibly related to attractiveness appraisal, either for the P100 time range (Pizzagalli, Regard, \& Lehmann, 1999) or for the P100 and subsequent N170 and P200 components (Halit, de Haan, \& Johnson, 2000). However, these studies were not conclusive about the specific role of attractiveness because they used either portraits of pathologically deformed (Szondi) faces (Pizzagalli et al., 1999) or artificially distorted portraits (Halit et al., 2000). In sum, it appears that the attractiveness of faces may be appraised rather rapidly, with a time course that is comparable to the processing of other affect-related dimensions in both faces and nonface objects, but as yet the evidence is scarce and requires more direct corroboration.

The primary aim of the present study was to investigate whether faces of varying attractiveness would elicit dissociable ERPs and at which points in time such a modulation would occur. To this end, it seemed important to take into account the interindividual variability of attractiveness judgments. Although attractiveness can be related to certain common perceptual features, as mentioned above, there is also considerable interindividual variance in judgments of physical attractiveness (Feingold, 1992). This fact was accounted for in the present study by sorting the stimuli according to the participants' individual ratings as well as by an additional, item-specific analysis. A further aim of the study was to investigate whether attractiveness appraisal is mandatory whenever a face is seen, or whether instead it depends on the viewer's task or processing strategy. Therefore, ERPs were measured not only during attractiveness ratings but also while participants performed a gender decision task on the faces.

\section{METHOD}

\section{Participants}

Eighteen students ( 13 female, 5 male; mean age $24.2 \pm 3.54$ years) contributed data to the experiment. Three additional data sets were discarded because of technical problems or excessive ERP artifacts; all of the remaining participants were right-handed and reported normal or corrected-to-normal vision. The study was conducted in accordance with the Declaration of Helsinki, and all participants gave informed consent to participation in the study and were compensated with course credit or $€ 8 / \mathrm{h}$.

\section{Stimuli}

The stimulus set consisted of 114 color portraits of different young adult persons ( 57 female, 57 male). The persons depicted had been recruited through several model agencies, and the portraits were taken by a professional photographer under identical studio conditions. The portraits were standardized with respect to frontal view and frontal gaze direction, resolution (300 dpi), and lighting. Accessories (e.g., jewelry or hair clips) were avoided, makeup was restricted to eyeliner, and no clothes were in view. The original portraits were reframed to ensure identical display windows and were placed in front of a standardized light gray background. All models had been informed about the photographer's cooperation with the authors of this study and had given written consent for the use of their portraits for scientific purposes.

To control for a possible impact of facial affect on attractiveness judgments, we conducted a computer-assisted preexperimental rating of emotional expression, which included 20 students ( 14 female, 6 male; mean age $26.7 \pm 5.04$ years) who did not overlap with the ERP study. On a scale from 1 (very happy) to 7 (very angry), the mean emotion ratings of the portraits ranged between 2.55 and 5.40 $(M=3.84, S D=0.64)$. Mean itemwise attractiveness ratings in the present experiment were moderately correlated with these emotion ratings $(r=.34, p<.001)$.

\section{Procedure}

The participants were seated in a dimly lit, sound-attenuated, and electrically shielded room. The portraits were presented on a com- 
puter screen at a distance of $80 \mathrm{~cm}$ and a size of $10.5 \times 8 \mathrm{~cm}$. The ERP experiment consisted of two parts, gender decision and attractiveness rating. During the first part of the experiment, participants classified the portraits according to gender by pressing the left or right mouse key with their dominant hand as quickly and accurately as possible. Each trial began with a fixation cross $(600 \mathrm{msec})$, followed by a 50 -msec blank screen, a face stimulus $(1,500 \mathrm{msec})$, and an interval of 2,400 msec until the beginning of the next trial, during which the participants were asked to blink if necessary. Gender-tokey assignments were counterbalanced across participants.

In the second part of the experiment, participants rated the portraits for facial attractiveness on a 7-point scale, displayed horizontally below each portrait. The scale consisted of seven verbally labeled fields of equal size (very attractive, attractive, rather attractive, neither-nor, rather nonattractive, nonattractive, and very nonattractive). The field corresponding to the estimated attractiveness value had to be clicked with the mouse. After the click, the cursor vanished and reappeared, together with the next portrait at a midline position. The participants were encouraged to utilize the whole scale for their ratings.

The trial structure during the attractiveness rating was identical to that during the gender decision task, except for a longer face presentation time $(3,000 \mathrm{msec})$. Each experimental part involved three blocks with randomized presentation of all portraits within each block. Thus, each face was presented once per block and six times in all. At the beginning of each experimental part, the participants performed six practice trials with portraits not otherwise used in the study. The duration of the experiment was about $45 \mathrm{~min}$, including short breaks in the middle and at the end of each block. To ensure that participants were naive to the research question of the experiment, the gender decision block always preceded the attractiveness evaluation block, and facial attractiveness was not mentioned prior to the latter block. After the experiment, the participants were informed in detail about the aims of the study.

\section{Electroencephalogram (EEG) Data Recording}

Recordings were made from $\mathrm{Ag} / \mathrm{AgCl}$ electrodes mounted in an electrode cap (Easy-Cap) at 32 scalp positions (FP1, FP2, F3, F4, F7, F8, F9, F10, FT9, FT10, C3, C4, T7, T8, TP9, TP10, P3, P4, P7, P8, P9, P10, PO9, PO10, O1, O2, Fpz, Fz, Cz, Pz, Oz, Iz) according to the extended 10-20 system. The horizontal electrooculogram (EOG) was recorded from the FT9 and FT10 electrodes, and the vertical EOG was monitored from FP1, FP2, and two additional electrodes below each eye. The TP9 electrode was taken as the initial common reference, and AFz served as the ground. Impedances were kept below $5 \mathrm{k} \Omega$. All signals were amplified using BrainAmp amplifiers and were recorded with a band-pass of $0.032-100 \mathrm{~Hz}$, a $50-\mathrm{Hz}$ notch filter, and a sampling rate of $250 \mathrm{~Hz}$.

\section{Data Analysis}

Behavioral responses in the gender decision task were scored as correct if the appropriate key was pressed between 100 and $1,500 \mathrm{msec}$ after target onset. For the gender classification task, only correct classifications were considered, whereas all responses were accepted for the attractiveness rating task. Mean reaction times (RTs) were analyzed by repeated measures ANOVAs involving the factors facial attractiveness and portrait gender.

For the ERP analysis, epochs of 1,200 msec were generated offline from the continuous EEG records, starting $200 \mathrm{msec}$ before stimulus onset. Trials with artifacts, saccades, blinks, or incorrect behavioral responses (in the case of gender decisions) were discarded. ERPs were aligned to a $200-\mathrm{msec}$ baseline. Thereafter, they were averaged separately for each channel and experimental condition, low-pass filtered at $30 \mathrm{~Hz}$, and recalculated to an average reference, excluding the two electrodes below the eyes.

Average ERP waveforms for both gender decision and attractiveness ratings were calculated separately. In a first step, three attractiveness categories were defined for both tasks on the basis of the distributions across participants of the mean rating values of all 114 portraits. These categories included mean rating values from 1.0 to 3.0 for attractive, 3.3 to 5.3 for intermediate, and 5.7 to 7.0 for nonattractive faces. The ERP responses to each portrait for a given participant were assigned to one of these categories, depending on the average attractiveness rating of the participant for this portrait. Thus, in this type of analysis, the ERPs to a given portrait elicited in different participants could be assigned to the same or to different attractiveness categories, depending on the participants' individual attractiveness ratings.

The ERPs from the attractiveness rating condition were analyzed in two further ways: an idiosyncratic five-bin analysis and an itemwise analysis. The five-bin analysis was performed for two reasons. First, it allowed for a more fine-grained analysis of attractiveness effects. Second, idiosyncratic distributions of ratings - for example, biases toward one of the poles or toward the middle of the scale - could be considered to a greater extent. In this analysis, the rating distribution of each participant was partitioned into five bins that contained approximately equal numbers of the rated stimuli. ERP averaging then took place according to these five idiosyncratic bins.

Finally, the relationship between emotional significance and possible ERP effects was analyzed at the item level. ERPs and attractiveness ratings were averaged for each item across the three presentations per participant as well as across the 18 participants.

ERP segmentation was based on visual inspection of measures of global field power (GFP; Lehmann \& Skrandies, 1980) and global map dissimilarity (GMD; Brandeis, Naylor, Halliday, Callaway, \& Yano, 1992). GFP reflects the overall ERP activity across the scalp at any given moment. GMD shows the dissimilarity between scalp topographies of adjacent time points and demarcates the borders between periods of relatively invariant topographies.

Mean amplitudes were assessed separately for each task, using repeated measures ANOVAs including the factors attractiveness and electrode site. By definition, the average reference sets the mean value of the ERP amplitude to zero across all electrodes within a given condition. Therefore, in these ANOVAs, only effects in interaction with electrode site are meaningful. The Huynh-Feldt correction was applied to adjust the degrees of freedom of the $F$ ratios. Please note that all of the repeated within-subjects ANOVA measures will be reported with corrected degrees of freedom as well as corrected $p$ values. To analyze whether any interactions of the experimental conditions with the electrode factor related to differences in amplitude, ANOVAs with GFP measures were calculated. For pairwise comparisons, the alpha levels were Bonferroni corrected.

Dipole source modeling of the early attractiveness effect was performed with the Brain Electromagnetic Source Analysis program (BESA, version 5.1; Scherg \& Berg, 2000) with a four-shell spherical head model (i.e., brain, bone, cerebrospinal fluid, and scalp).

\section{RESULTS}

\section{Performance}

According to the three attractiveness categories based on the distributions of mean rating values, $33 \%$ of all facial stimuli were classified as nonattractive and $27 \%$ as attractive; the remaining $40 \%$ were of intermediate attractiveness. The mean RTs (with $S D$ s in parentheses) during gender classification of the attractive, intermediate, and nonattractive faces were, in order, 571.3 (18.7), 566.4 (18.7), and 569.9 (16.9) msec. ANOVAs did not indicate any effects of attractiveness and portrait gender on the speed of gender classification $(F \mathrm{~s}<1)$. As expected, RTs during the 7-point attractiveness ratings, which required mouse movements and clicks, were much longer than those during dichotomous gender classifications, but the RTs did not differ across the three attractiveness bins $(M \mathrm{~s}=1,160.6,1,206.6$, and $1,171.3 \mathrm{msec} ; F<1)$. 


\section{ERP Data}

The GFP measures of ERPs for the three-bin classification are depicted in Figure 1. Visual inspection shows that attractiveness had little effect during gender classification, but during attractiveness rating it increased GFP for attractive and nonattractive faces relative to the intermediate ones. The following time segments of the ERPs were obtained from the transition times of GMD (Figure 1, bottom panel): 0-108, 108-144, 144-164, 164-188, and 188-292 msec. Mean ERP amplitudes were calculated for these intervals. After $292 \mathrm{msec}$, no clear segment borders were indicated by GMD. Therefore, consecutive time periods of 100-msec duration were selected for further analyses of the mean amplitudes between 292 and 792 msec. The same time segments were used for the idiosyncratic five-bin analysis.

ANOVAs of the ERP segments involving the factors attractiveness and electrode site during the gender decision (Figure 2, left panel) revealed a single significant but rather small effect of attractiveness for the 100-msec segment starting at $592 \mathrm{msec}[F(8,144)=2.0, p<.05]$. However, all pairwise comparisons for this segment failed to reach significance $(F \mathrm{~s}<2.7, p>.05)$.

The ANOVA results for ERPs recorded during the attractiveness ratings (Figure 2, right panel), involving the factors attractiveness (three levels) and electrode site, revealed significant effects of facial attractiveness in all time segments after $144 \mathrm{msec}(F \mathrm{~s}>2.0, p \mathrm{~s}<.05$; see Table 1$)$. In the following, ERP modulations prior to $188 \mathrm{msec}$ will be referred to as early effects because they were clearly located prior to the LPC time window, and they will be reported separately from later ERP effects.

Early ERP effects of attractiveness. The first significant effect of attractiveness, appearing between 144 and $164 \mathrm{msec}$, consisted of significant differences between nonattractive faces and faces of intermediate attractiveness $[F(8,136)=4.3, p<.01]$. When GFP measures were analyzed within this time period, no significant effect of

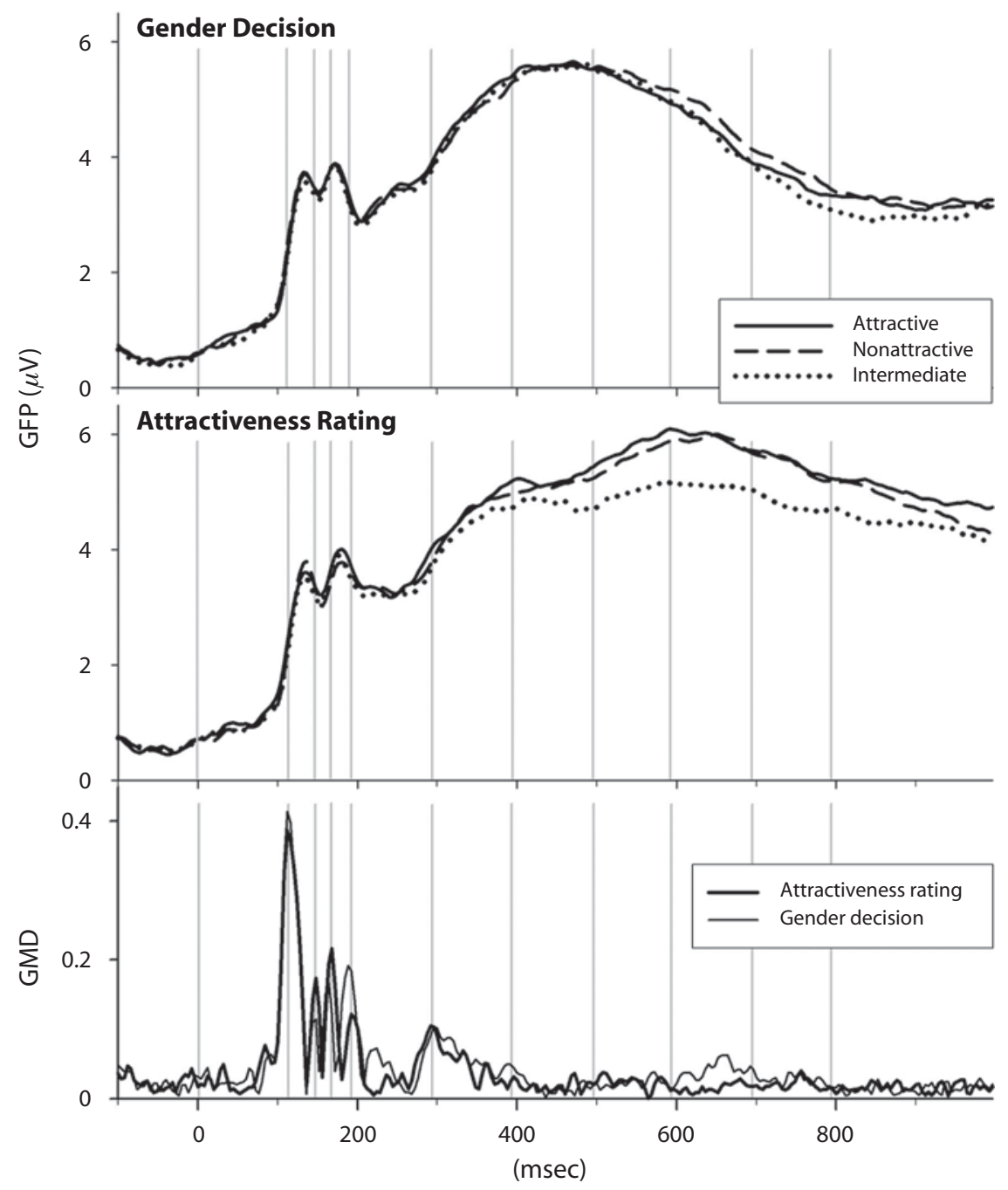

Figure 1. Global map dissimilarity (GMD) and global field power (GFP) of ERPs for the gender decision (top) and attractiveness rating (bottom) tasks. The vertical gray lines mark the segment borders, defined by GMD peaks. 


\section{Gender Decision}

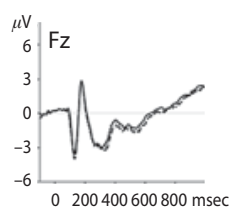

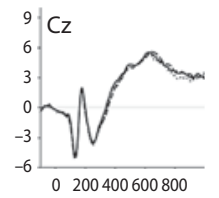

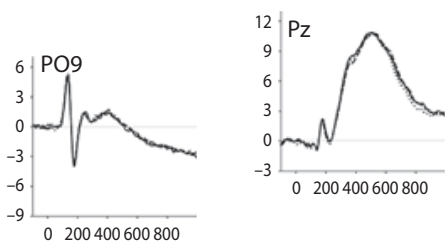

0200400600800
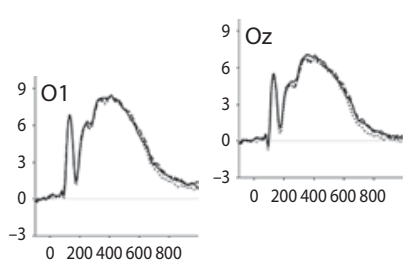
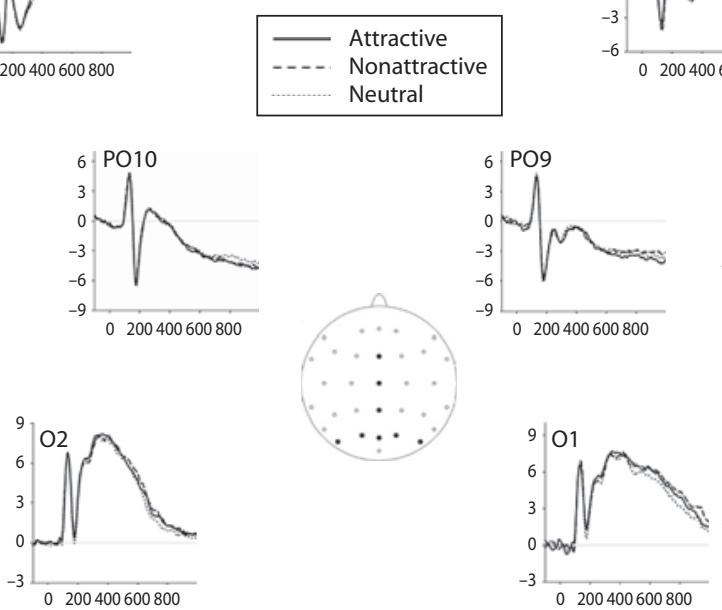

Attractiveness Rating

Figure 2. Grand mean ERPs to attractive, nonattractive, and intermediate faces at central and posterior electrode sites in both the gender decision (left) and attractiveness rating (right) tasks.

attractiveness appeared. In the subsequent time window, between 164 and $188 \mathrm{msec}$, pairwise comparisons revealed significant differences between attractive and intermediate faces $[F(5,81)=5.6, p<.001]$, whereas differences between nonattractive and intermediate faces appeared as a trend $[F(6,100)=2.7, p=.054]$. As depicted in Figure $3 \mathrm{~A}$, these early effects were characterized by positivities at posterior electrodes and frontal negativities.

As can be seen in Figure 3A, the attractiveness effects during the first two segments (144-164 and 164-188 msec) showed similar topographies, with positivities at posterior electrodes and frontal negativities, although they emerged in different comparisons (nonattractive vs. intermediate and attractive vs. intermediate faces, respectively). Therefore, mean ERP amplitudes in these two segments were compared directly in an ANOVA involving the factors time segment, attractiveness, and electrode site. Interestingly, this ANOVA revealed significant main effects of segment $[F(3,55)=26.0, p<.001]$ and attractiveness $[F(10,172)=2.8, p<.01]$, but the interaction of both factors failed to reach significance $[F(5,90)<1.7]$. Furthermore, when averaging ERPs across both segments, pairwise comparisons showed significant differences between faces of intermediate attractiveness and both attrac- tive $[F(5,81)=4.7, p<.01]$ and nonattractive $[F(6,99)=$ $3.8, p<.01]$ faces, whereas ERPs to attractive and nonattractive faces were indistinguishable $[F(4,73)<1, p>$ $.05]$. No significant interactions of attractiveness and segment appeared in these pairwise comparisons $(F \mathrm{~s}<$ $2.5, p \mathrm{~s}>.05)$. In addition, we conducted an ANOVA after normalizing with the vector method (McCarthy \& Wood, 1985) that did not reveal any significant difference between the scalp distributions of both difference waves, nonattractive minus intermediate faces $(144-164 \mathrm{msec})$, and attractive minus intermediate faces $(164-188 \mathrm{msec})$ $[F(5,77)=0.560, p>.7]$. Therefore, it appears that the early attractiveness effects were quite similar across attractiveness polarities and time segments. The following analyses probed into the nature of these early effects, especially into whether they relate to the simultaneously active N170 component.

To investigate whether the N170 component itself was influenced by attractiveness, we obtained peak amplitudes from the PO10 electrode site in a latency time segment from 120 to $200 \mathrm{msec}$ and submitted them to statistical analysis. Whereas an ANOVA revealed no effect of attractiveness on peak amplitudes $[F(2,34)=0.42, p>.05]$, peak latencies tended to be modulated by facial attractive-

Table 1

$F$ Values and Significance Levels of ANOVA Results for ERP Mean Amplitudes and

Global Field Power (GFP) During Attractiveness Classifications in Selected Time Segments (in Milliseconds), Involving the Factors Facial Attractiveness and-for Mean Amplitudes-Electrode Site

\begin{tabular}{|c|c|c|c|c|c|c|c|c|c|c|}
\hline & $0-108$ & $108-144$ & $144-164$ & $164-188$ & $188-292$ & $292-392$ & $392-492$ & $492-592$ & $592-692$ & $692-792$ \\
\hline Mean amplitude & 1.2 & 1.7 & $2.3^{*}$ & $3.0^{* * *}$ & $2.1^{*}$ & $2.2^{*}$ & $3.0^{* *}$ & $6.1^{* * *}$ & $7.7^{* * *}$ & $7.2^{* * *}$ \\
\hline GFP & 0.4 & 1.1 & 1.0 & 1.8 & 1.9 & $4.6^{* *}$ & $5.4^{* *}$ & $13.6^{* * *}$ & $15.2^{* * *}$ & $13.4^{* * *}$ \\
\hline
\end{tabular}


A

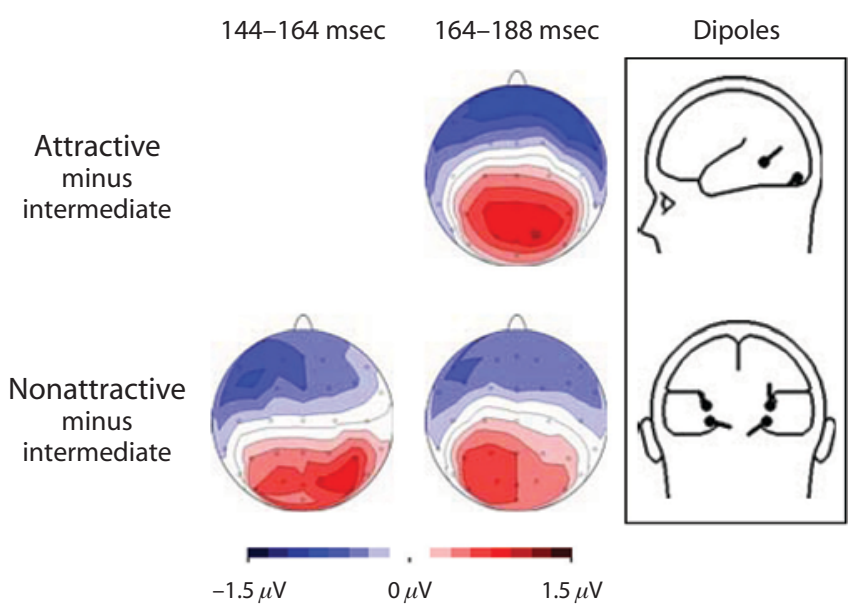

\section{Late Effects of Attractiveness}

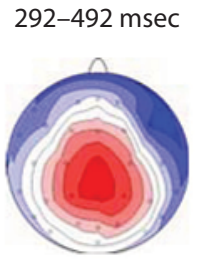

492-792 msec
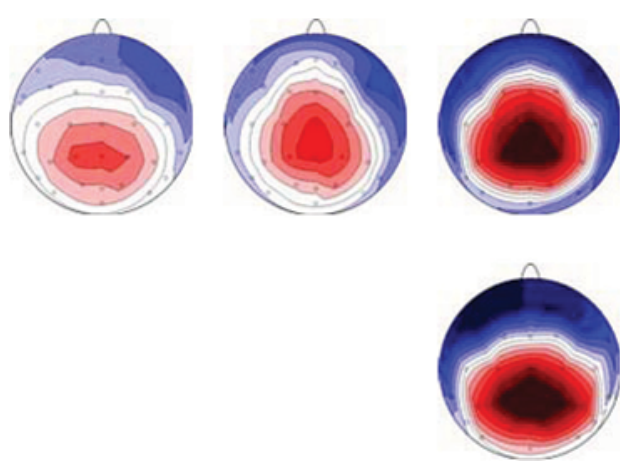

B

P100

116-152 msec
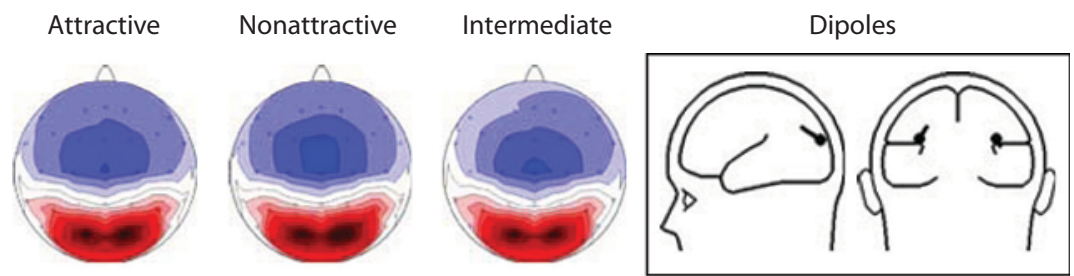

$\mathrm{N} 170$

156-196 msec
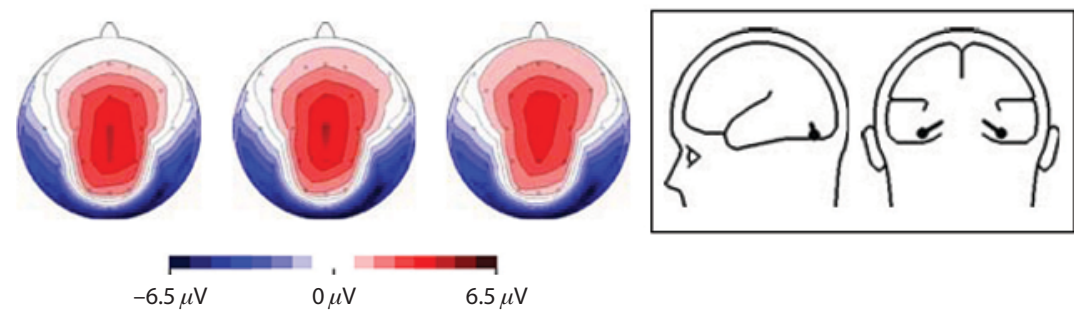

$0 \mu \mathrm{V}$

$6.5 \mu \mathrm{V}$

Figure 3. Scalp distributions and dipole models of ERPs during attractiveness ratings. (A) Early and late attractiveness effects, depicted as topographies of difference waves between ERPs for attractive and nonattractive relative to intermediate faces. Left side of panel: Scalp distributions of the early attractiveness effect and equivalent dipoles for this effect. Right side of panel: Late effects of facial attractiveness. (B) Scalp distributions of the P100 and the N170 components for the three attractiveness categories (left) and equivalent dipoles of these components (right) for the intermediate condition. Note the dissimilarity of these topographies with those of the attractiveness effects above.

ness $[F(2,34)=3.2, p=.052]$, since they were slightly prolonged for both attractive and nonattractive faces relative to the intermediate faces.

Figure 3B depicts the scalp distributions of the first visual ERP components - the P100 and the N170 - for all conditions of attractiveness, as well as the topography of the difference waves between attractive or nonattractive faces versus intermediate ones in the time segments in which these differences were significant. Note that although the first effect of attractiveness covered the time range of the N170, the scalp distribution of this effect appears rather different from the N170 topography. We verified this impression by an ANOVA with normalized data, which revealed significant differences between the distribution of the N170 (taken from the intermediate condition) and the difference wave of nonattractive and attractive (averaged over both conditions) minus intermediate faces $[F(5,85)=$
$11.7, p<.001]$. Visual inspection of the scalp distributions of the difference wave appears to indicate a similarity to the topography of the preceding P100. However, profile analyses indicated that these topographies were also significantly different $[F(7,122)=4.0, p<.01]$.

Although these results indicate that the neural sources of early attractiveness effects are different from those of both the P100 and N170 components, the spatial and temporal distribution of this early attractiveness effect might be due to a combined and overlapping effect of attractiveness on a late part of the P100 and on the consecutive N170 component. In order to distinguish such modulations of the P100 and N170 from separate, attractiveness-dependent activity, we modeled equivalent dipoles of these components. Such superimpositions should result from the accumulated activity of different neural sources-each generating one of the ERP components when attractive 
and nonattractive faces are processed. Therefore, in a first step, dipole models were obtained for the P100 and N170 components to faces of intermediate attractiveness (see Figure $3 \mathrm{~B}$ ). For both components, principal component analysis (PCA) indicated one component that explained more than $99 \%$ of the variance. For the P100, a symmetric dipole pair was located in the middle occipital gyrus (Talairach \& Tournoux [1988] coordinates: $x= \pm 35 \mathrm{~mm}$, $y=-91 \mathrm{~mm}, z=+16 \mathrm{~mm}$; residual variance $<4 \%$ ). The neural sources for the N170 were located in the fusiform gyrus $(x= \pm 36 \mathrm{~mm}, y=-76 \mathrm{~mm}, z=-21 \mathrm{~mm}$; residual variance $<5 \%$ ). As indicated by the profile analysis above, distributions of the early effects of nonattractive and attractive faces were comparable. Therefore, grand average difference waves for both nonattractive and attractive minus intermediate faces were used to derive neural source models. Spatial PCA of the 144-188 msec segment indicated two principal components explaining $98 \%$ of the variance in the data of the differences wave (PC1 explained $86.7 \%$ and $\mathrm{PC} 2,11.2 \%$ ). In a next step, we fixed the two dipole pairs from the P100 and the N170 in these difference wave data, which explained less than $60 \%$ of the variance. Finally, we modeled the non/attractiveness effect with two single dipoles with a symmetry constraint. These dipole pairs explained $97 \%$ of the variance in the difference wave and were located in the fusiform gyrus $(x= \pm 26 \mathrm{~mm}, y=-87 \mathrm{~mm}, z=-18 \mathrm{~mm})$ and the parahippocampal gyrus $(x= \pm 29 \mathrm{~mm}, y=-51 \mathrm{~mm}, z=$ $+2 \mathrm{~mm}$ ) (see Figure 3A).

Late ERP effects of attractiveness. Pairwise post hoc comparisons for the three-bin analysis in the late time period between 188 and 492 msec (segments: 188-292, 292-392, and 392-492 msec) revealed significant differences only between attractive and intermediate faces $(F \mathrm{~s}>3.6, p \mathrm{~s}<.05)$. Between 292 and $492 \mathrm{msec}$ - but not in the preceding segment - attractive faces showed stronger GFP than did intermediate faces.

Between 492 and $792 \mathrm{msec}$, both attractive and nonattractive faces elicited different ERPs, as compared with faces of intermediate attractiveness $(F \mathrm{~s}>6.5, p \mathrm{~s}<.001)$, whereas attractive and nonattractive faces were indistinguishable within these time segments $(F \mathrm{~s}<2.5, p \mathrm{~s}>$ $.05)$. As indicated by the ANOVAs with GFP measures, these effects appear to be related to differences in amplitude $(F \mathrm{~s}>12.1, p \mathrm{~s}<.01)$.

The following five-bin analysis was restricted to ERPs recorded during attractiveness ratings, since analysis on the basis of three-bin classifications revealed no significant effects in the gender decision task. Also, the resolution for the five-bin analysis appeared too weak to reveal clear effects during early time segments. Here, ERPs were averaged according to five attractiveness categories of about equal size, on the basis of the distribution of each participant's individual attractiveness ratings. Mean amplitudes of GFP were assessed by a repeated measures ANOVA, which revealed main effects of facial attractiveness in all time segments $(F \mathrm{~s}>10.0, p \mathrm{~s}<.001)$ starting at $492 \mathrm{msec}$. As is shown in Figure 4A, these effects resulted from enhanced LPC amplitudes elicited by the most attractive and most nonattractive faces, as compared with all three inter- mediate attractiveness categories $(F \mathrm{~s}>13.3, p \mathrm{~s}<.001)$. In contrast, neither the three intermediate $\left(F_{\mathrm{s}}<2.3, p \mathrm{~s}>\right.$ $.05)$ nor the two extreme attractiveness categories $(F \mathrm{~s}<$ $2.4, p \mathrm{~s}>.05)$ were distinguishable from each other. Both maps of difference waves - attractive versus intermediate and nonattractive versus intermediate faces - show a topography with a centroparietal positivity, which is typical for the LPC (see right panel of Figure 3A).

As described above, ERPs were also averaged itemwise for each portrait across the three presentations during the attractiveness rating and across the 18 participants; that is, the ERP for each of the 114 portraits was based on 54 responses, disregarding unavoidable losses due to artifacts. For these 114 ERP wave shapes, average mean amplitudes at the Pz electrode were calculated during the LPC segment between 492 and 792 msec. Figure 4B shows a U-shaped relationship between the mean attractiveness rating values and LPC amplitudes at the Pz electrode. This relationship was confirmed by a strong quadratic trend $\left[F(113)=30.5, p<.001, r^{2}=.351\right]$, whereas a linear
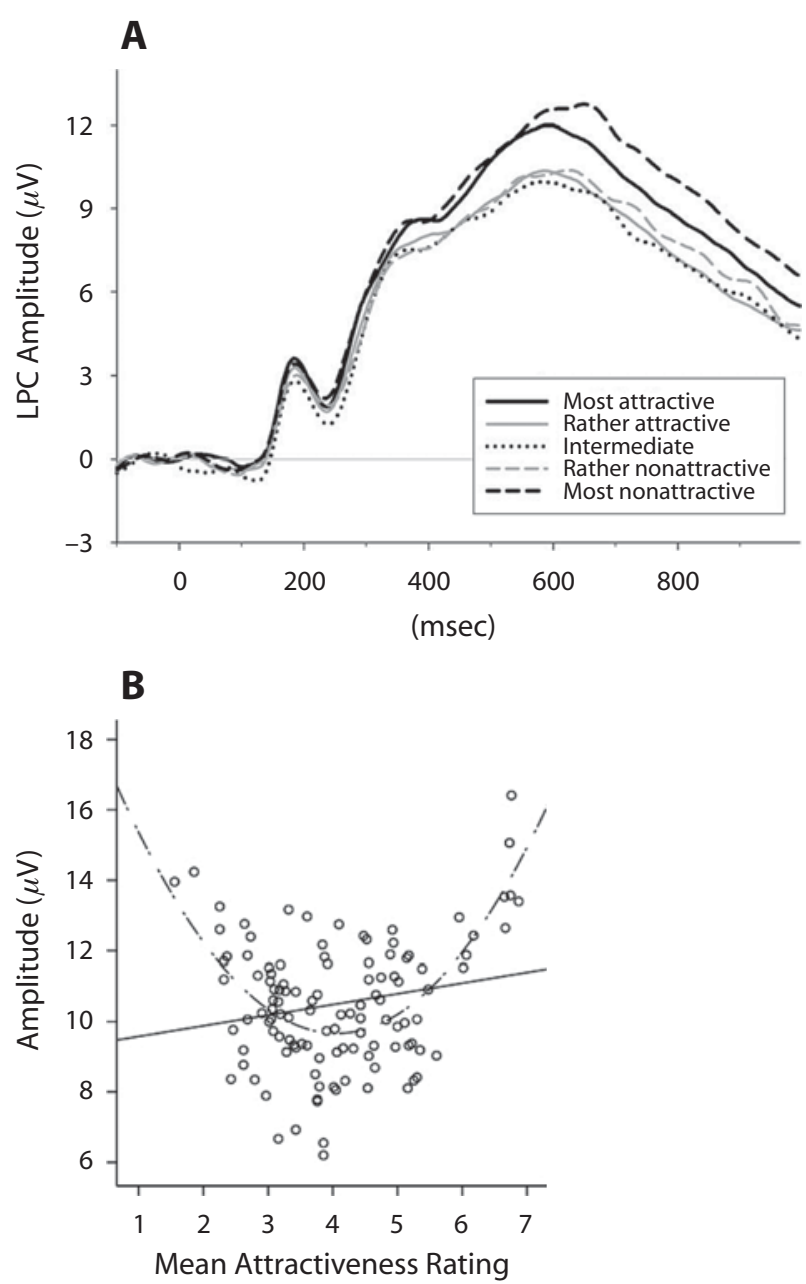

Figure 4. Late attractiveness effects at the $\mathrm{Pz}$ electrode. (A) Grand mean ERPs for the idiosyncratic five-bin analysis. (B) Itemwise relationship between mean attractiveness ratings and LPC amplitudes at the Pz electrode between 492 and 792 msec. 
trend was significant but much smaller $[F(114)=4.5$, $\left.p<.05, r^{2}=.038\right]$. In order to account for any contributions of emotional expression to the relationship between attractiveness and LPC amplitude, we calculated the regressions after partialing out emotional expression from attractiveness. The U-shaped relationship between attractiveness and LPC amplitude increased slightly $[F(113)=$ 43.3, $\left.p<.001, r^{2}=.421\right]$ after taking into account emotional expression, but the linear trend dropped to nonsignificance $\left[F(114)=2.4, p>.05, r^{2}=.019\right]$.

\section{DISCUSSION}

The present experiment assessed whether and when facial attractiveness - subjectively appraised by the observer-would affect the processing of faces, as reflected by scalp-recorded brain potentials. In addition, we were interested in whether attractiveness appraisal would depend on the task performed on the face. As main results, two qualitatively different effects of attractiveness appeared in the ERPs, an early effect around $150 \mathrm{msec}$ and a later one starting around $300 \mathrm{msec}$. Interestingly, although both ERP effects clearly differed in latency, they shared two important features: First, both appeared when facial attractiveness was task relevant but were mostly absent when the faces were categorized for gender. Second, these effects appeared similarly for both attractive and nonattractive faces, as compared with intermediate faces.

A main result of the present study is the observation of an early effect of facial attractiveness starting around $150 \mathrm{msec}$. This finding confirms several previous reports indicating that facial attractiveness might be processed rapidly. For instance, Olson and Marshuetz (2005) found that even very little information may be sufficient for attractiveness appraisal, but their behavioral study provided only limited evidence about the temporal localization of the effect. Further supporting evidence comes from studies reporting early ERP effects for emotional dimensions other than attractiveness (e.g., Pizzagalli et al., 1999). Extending these previous findings, the present study showed that the attractiveness dimension can have differential effects on brain activity at least as early as other emotional or affective stimulus dimensions, such as emotional facial expressions (Schupp, Öhman, et al., 2004; Schutter et al., 2004), emotional connotations of written words (Kissler, Herbert, Peyk, \& Junghöfer, 2007), or affective content of pictures (Schupp et al., 2003a, 2003b). In this respect, our findings are in line with our earlier study revealing an ERP effect around $250 \mathrm{msec}$ poststimulus (Werheid et al., 2007), notwithstanding the differences in timing and scalp distributions of the early attractiveness effects in both experiments, which may have been due to differences in the variability and number of the faces employed or in task demands (attractiveness rating vs. binary classification).

Interestingly, the early ERP modulation covered the time range of the N170, a component that has been related to configural processing of facial features and holistic face perception (see, e.g., Bentin \& Deouell, 2000; Schweinberger, Pickering, Jentzsch, Burton, \& Kaufmann, 2002) and to structural encoding of faces (Bruce \&
Young, 1986). However, our data showed that N170 peak amplitudes were not affected by facial attractiveness (see Eimer et al., 2003; Schacht \& Sommer, 2008), and N170 slopes to attractive and nonattractive faces were only slightly delayed relative to those to intermediate faces. This prolongation is rather small in comparison with the sizeable and reliable increases of N170 latencies found in previous research, for example in response to inverted faces, which pose increased demands on holistic face perception (e.g., Rossion et al., 1999; but see Latinus \& Taylor, 2006). Also, it is hard to see how increased demands on holistic face perception might account for the early attractiveness effect found in the present study. Another assumption could be that such latency effects might reflect differences in the duration of initial visual processing. This idea appears to be supported by the observation that the topography of the attractiveness effect showed a pattern somewhat similar to that of the P100 component. However, topographical comparisons indicated that the early attractiveness effect did not entirely match the P100 itself. Furthermore, on the basis of our dipole models, we can rule out that this effect resulted from a superposition of P100 and N170, since combining the dipole sources of these components was insufficient to account for the early attractiveness effect in the ERP. Instead, further dipole localizations in this time interval, conducted without spatial constraints, yielded two dipole pairs that were located in the fusiform gyrus and the parahippocampal gyrus. Within this network, the parahippocampal gyrus may act as a gate between extrastriate areas and emotion-related subcortical limbic structures, which may be involved in registering attractiveness but cannot be directly observed in ERPs. However, these findings suggest that the processing of attractiveness engages a network that is independent of those systems responsible for generating the P100 and N170 components.

Recently, Vuilleumier and Driver (2007) proposed that both attentional and emotional effects on visual perception are due to top-down influences upon the visual cortex from brain regions farther upstream. Although the upstream networks may differ, their effects on processing in peristriate cortex consist of similar activation patterns. Both the time course and the dipole model of our early ERP effects support this assumption of enhanced perceptual analysis of attractive and nonattractive faces in inferotemporal brain structures. In contrast with other emotional dimensions, there is no direct evidence for increased activation in peristriate or striate areas from imaging studies. Possibly such attractiveness effects have remained undetected because of a focus on such tasks as passive viewing (e.g., Aharon et al., 2001) or gender judgment (e.g., O'Doherty et al., 2003).

The intriguing observation that ERP modulations appeared to be comparable for both attractive and nonattractive faces relative to intermediate ones also held for the later LPC effect. Many previous studies have shown that LPC amplitude is related to the emotional content of a stimulus. This has also been true for previous studies that directly investigated attractiveness and found larger LPC amplitudes between 400 and $600 \mathrm{msec}$ for attractive than 
for less attractive faces (Johnston \& Oliver-Rodríguez, 1997; Oliver-Rodríguez et al., 1999; Werheid et al., 2007). Two observations from the present study are at variance with these previous reports. First, LPC modulations, consisting of enhanced amplitudes to attractive relative to intermediate faces, started about $200 \mathrm{msec}$ earlier than in the studies mentioned above. Second, in later time segments, the relationship between attractiveness ratings and LPC amplitudes was not monotonic or even linear, since the linear trend was small and vanished when the moderate relationship between the valence of facial expression and attractiveness was taken into account. This U-shaped relationship between attractiveness and ERP amplitude was especially clear in the idiosyncratic five-bin and itemwise analyses, which mainly showed differences between the intermediately attractive faces and the positive and negative extremes, respectively, but none between the extreme attractiveness categories after around $490 \mathrm{msec}$.

A possible explanation for the discrepancies between the present and previous findings is related to stimulus characteristics and task requirements. Whereas the present study used high-quality color photographs, the studies of Johnston and coworkers (Johnston \& Oliver-Rodríguez, 1997; Oliver-Rodríguez et al., 1999) employed schematic line drawings with electronically manipulated proportions. Furthermore, in comparison with our previous study (Werheid et al., 2007), the present study used a wider range of stimuli with regard to facial attractiveness, indicated by comparing the attractiveness ratings of both experiments. Further differences between the present and previous studies concern the task demands. In the studies of Johnston and coworkers, no task had to be performed on facial stimuli while ERPs were recorded. In our own previous study, dichotomous decisions between attractive and nonattractive faces had to be made. Obviously, the direct evaluation of attractiveness on a scale ranging from very nonattractive to intermediate to very attractive faces establishes an internal continuum with two clearly defined poles, as well as a reference point that it has been suggested is derived from continuous updating of stimulus representations (Helson, 1964). The finding that emotion-related LPC effects are affected by response mode should be considered in further ERP research. Several studies have shown the P300 to reflect, besides emotional dimensions, the distance between a current stimulus (mostly numerical or a symbol) and a reference point derived from an internal model about relevant stimuli (see, e.g., Ullsperger \& Grune, 1995). The clear U-shaped relationship between attractiveness ratings and LPC amplitudes might therefore arise from the maximal distance of very non/attractive faces from the reference point- derived from intermediate faces.

Notably, however, the present findings are in line with previous research reporting LPC modulations in response to affective pictures. Several studies have shown that both pleasant and unpleasant pictures elicit an enlarged LPC as compared with neutral pictures (e.g., Cuthbert et al., 2000; Schupp et al., 2000; Schupp, Junghöfer, et al., 2004). Since the effect of positive emotional valence is similar, albeit somewhat smaller, than that for negative valence, this effect has been attributed to the emotional stimuli's increased motivational significance and arousal value (e.g., Kayser et al., 1997; Schupp et al., 2000). Enhanced P300 amplitudes for nonemotional stimuli were found when the ERP-eliciting stimulus was attended (e.g., Johnson, 1988), infrequent, or task relevant (e.g., Picton \& Hillyard, 1988). Thus, the P300 is considered to be an ERP component elicited by active cognitive analysis of relevant stimuli (see Bashore \& van der Molen, 1991, for a review). In the case of emotional stimuli, enhanced P300/ LPC amplitudes have been suggested to reflect increased continued analysis initiated by the increased intrinsic relevance of emotional stimuli (Lang, Bradley, \& Cuthbert, 1997). We therefore suggest that the augmented LPC amplitudes to attractive as well as to nonattractive faces found here reflect their enhanced elaborative analysis as compared with intermediate faces - resulting from augmented perceptual analysis, as possibly reflected in the early ERP effect described above.

Further clues for the interpretation of our attractiveness effects in ERPs come from results regarding the influence of the task factor, which was used to investigate whether attractiveness is appraised in an automatic and task-independent fashion. During gender decision, both the early and late ERP modulations were absent orconsidering the small effect in one of the LPC intervals at least very much reduced. Thus, both the early and late attractiveness modulations of our ERPs were highly susceptible to task factors. This is in contrast to early reports with affective pictures, which have shown both early ERP and LPC modulations, even when a cognitive attention task was performed concurrently to viewing the pictures (Schupp et al., 2003b). However, our results are in line with other studies that have shown that emotion effects in the LPC are modulated by task demands (Diedrich, Naumann, Maier, Becker, \& Bartussek, 1997; Eimer et al., 2003; Hajcak, Moser, \& Simons, 2006; Schupp et al., 2007).

Schupp et al. (2003a) suggested that the emotiondependent ERP modulations with affective pictures result from reflective visual attention facilitating sensory encoding, as reflected by early ERP components, which in turn cause enhanced continued processing (an LPC). The researchers considered these effects of affect to be analogous to those of orienting attention toward a specific location in space (Mangun, Jha, Hopfinger, \& Handy, 2000). For the present case of attractiveness, such reflexive attention allocation does not seem to hold. Moreover, the appraisal of attractiveness does not appear to be a mandatory process, invoked whenever a face is perceived. Instead, attractiveness appraisal seems to require voluntary attention to the attractiveness dimension and may compete with other resource-drawing processes, even when the face as such is the focus of attention, as is the case during gender decisions. This is in line with findings from studies on similar judgments in other domains. Recently, Höfel and Jacobsen (2007) showed LPC effects to graphic patterns to be restricted to explicit aesthetic categorization; the LPC effect did not appear spontaneously when no overt response was required.

Similar to Schupp et al.'s (2003a) account of emotion effects on ERPs, we propose that the present ERP findings 
can be explained by the allocation of attention to attractive and nonattractive faces, resulting in enhanced elaborative processing. However, in facial attractiveness, the allocation of attention does not seem to be mandatory, because the effects were absent in the gender classification task - that is, when attention was allocated to task-relevant dimensions other than attractiveness. Obviously, the internal continuum or reference point (see Ullsperger \& Grune, 1995) of facial attractiveness - as far as it is reflected in ERP measures - is not derived automatically when the task requires decisions about faces that are unrelated to attractiveness.

The task dependency of the facial attractiveness effects in ERPs argues against an underlying mechanism tied in a reflexive, bottom-up fashion to sexual attraction or reproductive fitness. The same argument could be based on the similarity of the effects for attractive and nonattractive faces. Why should a mate-detecting system respond in the same way to both extreme values on the attractiveness scale?

When discussing the task dependency of our attractiveness effects, one must take into account that the sequence of tasks was not counterbalanced, since the gender decision always started the experimental session and was followed by the attractiveness rating task, in order to prevent attention allocation to attractiveness during gender decisions. Therefore, we cannot rule out that the internal continuum of facial attractiveness might be established over time - that is, with each repetition of the facial stimuli. Nevertheless, in our opinion the task sequence in the present experiment cannot explain the absence of attractiveness effects during gender decisions; if attractiveness were processed automatically and task-independently, it should have affected face processing from the beginning.

Finally, we would add a word of caution as to the specificity of the present findings for facial attractiveness. On a priori grounds, the task specificity of the present findings argues for a domain-general effect. That is, findings similar to the present ones might be obtained whenever aesthetic or other judgments are required on sets of stimuli that vary in a continuous fashion on one or several dimensions. From an empirical perspective, such domain generality is supported by the facts that the localization of the early effects was not tied to a presumably face-specific component, such as the N170, and further that similar effects have been observed for aesthetic judgments of nonface objects (Höfel \& Jacobsen, 2007). Nevertheless, the present effects seem to hold for facial attractiveness, and their generalizability to other objects or dimensions has to await further scrutiny.

In conclusion, facial attractiveness can modulate brain processes as early as $150 \mathrm{msec}$ after a face is encountered. The early effects appear to take place in a network that is independent of those responsible for visual and structural analysis (the P100 and N170 components) and is followed by the modulation of the LPC, possibly indicating enhanced continued processing. Both early and late effects are similarly prominent for attractive and nonattractive faces relative to intermediate ones. In contrast to findings from other emotional domains, the effects of attractiveness are strongly task dependent and vanish when faces have to be processed for other attributes. Thus, they may reflect the voluntary aesthetic appraisal of faces rather than bottom-up attention processes driven by sexual attractiveness.

\section{AUTHOR NOTE}

We thank Mareike Bayer, Maria Gruno, and Roland Nigbur for assisting in data collection, and Rainer Kniesche and Thomas Pinkpank for technical support. This research was supported by the German Research Foundation through Grant So 177/14-1 to W.S. Correspondence concerning this article should be addressed to A. Schacht, Department of Psychology, Humboldt University at Berlin, Rudower Chaussee 18, D-12489 Berlin, Germany (e-mail: schachta@hu-berlin.de).

Note-This article was accepted by the previous editorial team, when John Jonides was Editor.

\section{REFERENCES}

Aharon, I., Etcoff, N., Ariely, D., Chabris, C. F., O'Connor, E., \& Breiter, H. C. (2001). Beautiful faces have variable reward value: fMRI and behavioral evidence. Neuron, 32, 537-551.

BalConi, M., \& Pozzoli, U. (2003). Face-selective processing and the effect of pleasant and unpleasant emotional expressions on ERP correlates. International Journal of Psychophysiology, 49, 67-74.

Bashore, T. R., \& VAn der Molen, M. W. (1991). Discovery of the P300: A tribute. Biological Psychology, 32, 155-171.

Bentin, S., \& Deouell, L. Y. (2000). Structural encoding and identification in face processing: ERP evidence for separate mechanisms. Cognitive Neuropsychology, 17, 35-55.

Brandeis, D., Naylor, H., Halliday, R., Callaway, E., \& Yano, L. (1992). Scopolamine effects on visual information processing, attention, and event-related potential map latencies. Psychophysiology, 29, 315-336.

Bruce, V., \& Young, A. (1986). Understanding face recognition. British Journal of Psychology, 77, 305-327.

Cuthbert, B. N., Schupp, H. T., Bradley, M. M., Birbaumer, N., \& LANG, P. J. (2000). Brain potentials in affective picture processing: Covariation with autonomic arousal and affective report. Biological Psychology, 52, 95-111.

Diedrich, O., Naumann, E., Maier, S., Becker, G., \& Bartussek, D. (1997). A frontal positive slow wave in the ERP associated with emotional slides. Journal of Psychophysiology, 11, 71-84.

Eimer, M., Holmes, A., \& McGlone, F. P. (2003). The role of spatial attention in the processing of facial expression: An ERP study of rapid brain responses to six basic emotions. Cognitive, Affective, \& Behavioral Neuroscience, 3, 97-110.

ETCOFF, N. (1999). Survival of the prettiest: The science of beauty. New York: Doubleday.

FeIngOLd, A. (1992). Good-looking people are not what we think. Psychological Bulletin, 111, 304-341.

Fischler, I., \& BRAdLEy, M. (2006). Event-related potential studies of language and emotion: Words, phrases, and task effects. Progress in Brain Research, 156, 185-203.

HaJCAK, G., Moser, J. S., \& Simons, R. F. (2006). Attending to affect: Appraisal strategies modulate the electrocortical response to arousing pictures. Emotion, 6, 517-522.

Halit, H., DE HaAn, M., \& Johnson, M. H. (2000). Modulation of event-related potentials by prototypical and atypical faces. NeuroReport, 11, 1871-1875.

Helson, H. (1964). Adaptation-level theory: An experimental and systematic approach to behavior. New York: Harper \& Row.

HöFEL, L., \& JACOBSEN, T. (2007). Electrophysiological indices of processing aesthetics: Spontaneous or intentional processes? International Journal of Psychophysiology, 65, 20-31.

IsHAI, A. (2007). Sex, beauty and the orbitofrontal cortex. International Journal of Psychophysiology, 63, 181-185.

Johnson, R., JR. (1988). The amplitude of the P300 component of the event-related potential: Review and synthesis. In P. K. Ackles, J. R. Jennings, \& M. G. H. Coles (Eds.), Advances in psychophysiology (Vol. 3, pp. 69-138). Greenwich, CT: JAI Press. 
Johnston, V. S., \& Oliver-Rodríguez, J. C. (1997). Facial beauty and the late positive component of event-related potentials. Journal of Sex Research, 34, 188-198.

Kampe, K. K. W., Frith, C. D., Dolan, R. J., \& Frith, U. (2001). Reward value of attractiveness and gaze. Nature, 413, 589-590.

Kayser, J., Tenke, C., Nordby, H., Hammerborg, D., Hugdahl, K., \& ERDMANN, G. (1997). Event-related potential (ERP) asymmetries to emotional stimuli in a visual half-field paradigm. Psychophysiology, 34, 414-426.

Kissler, J., Herbert, C., Peyk, P., \& Junghöfer, M. (2007). Buzzwords: Early cortical responses to emotional words during reading. Psychological Science, 18, 475-480.

Kranz, F., \& IshaI, A. (2006). Face perception is modulated by sexual preference. Current Biology, 16, 63-68.

Lang, P. J., Bradley, M. M., \& Cuthbert, B. N. (1997). Motivated attention: Affect, activation, and action. In P. J. Lang, R. F. Simons, \& M. T. Balaban (Eds.), Attention and orienting: Sensory and motivational processes (pp. 97-135). Mahwah, NJ: Erlbaum.

Langlois, J. H., \& Roggman, L. A. (1990). Attractive faces are only average. Psychological Science, 1, 115-121.

LatinUs, M., \& TAYLOR, M. J. (2006). Face processing stages: Impact of difficulty and the separation of effects. Brain Research, 1123, 179-187.

LehmanN, D., \& Skrandies, W. (1980). Reference-free identification of components of checkerboard-evoked multichannel potential fields. Electroencephalography \& Clinical Neurophysiology, 48, 609-621.

Mangun, G. R., Jha, A. P., Hopfinger, J. B., \& Handy, T. C. (2000). The temporal dynamics and functional architecture of attentional processes in human extrastriate cortex. In M. S. Gazzaniga (Ed. in chief), The new cognitive neurosciences (2nd ed., pp. 701-710). Cambridge, MA: MIT Press, Bradford Books.

McCarthy, G., \& Wood, C. C. (1985). Scalp distributions of eventrelated potentials: An ambiguity associated with analysis of variance models. Electroencephalography \& Clinical Neurophysiology, 62, 203-208.

NaKamura, K., Kawashima, R., Nagumo, S., Ito, K., Sugiura, M., Kato, T., ET AL. (1998). Neuroanatomical correlates of the assessment of facial attractiveness. NeuroReport, 9, 753-757.

O’Doherty, J., Winston, J., Critchley, H., Perrett, D., Burt, D. M., \& Dolan, R. J. (2003). Beauty in a smile: The role of medial orbitofrontal cortex in facial attractiveness. Neuropsychologia, 41, 147-155.

Öhman, A., \& Mineka, S. (2001). Fears, phobias, and preparedness: Toward an evolved module of fear and fear learning. Psychological Review, 108, 483-522.

Oliver-RodríGuez, J. C., GuAn, Z., \& Johnston, V. S. (1999). Gender differences in late positive components evoked by human faces. Psychophysiology, 36, 176-185.

Olson, I. R., \& Marshuetz, C. (2005). Facial attractiveness is appraised in a glance. Emotion, 5, 498-502.

Peskin, M., \& Newell, F. N. (2004). Familiarity breeds attraction: Effects of exposure on the attractiveness of typical and distinctive faces. Perception, 33, 147-157.

Picton, T. W., \& Hillyard, S. A. (1988). Endogenous event-related potentials. In T. W. Picton (Ed.), Handbook of electroencephalography and clinical neurophysiology: Vol. 3. Human event-related potentials (pp. 361-426). Amsterdam: Elsevier.

Pizzagalli, D., Regard, M., \& Lehmann, D. (1999). Rapid emotional face processing in the human right and left brain hemispheres: An ERP study. NeuroReport, 10, 2691-2698.

Rhodes, G., Proffitt, F., Grady, J. M., \& Sumich, A. (1998). Facial symmetry and the perception of beauty. Psychonomic Bulletin \& Review, 5, 659-669.

Rhodes, G., \& Tremewan, T. (1996). Averageness, exaggeration, and facial attractiveness. Psychological Science, 7, 105-110.

Rossion, B., Delvenne, J.-F., Debatisse, D., Goffaux, V., Bruyer, R.,
Crommelinck, M., \& Guérit, J.-M. (1999). Spatio-temporal localization of the face inversion effect: An event-related potentials study. Biological Psychology, 50, 173-189.

Schacht, A., \& Sommer, W. (2008). Emotion in word and face processing: Early and late cortical responses. Manuscript submitted for publication.

Scherg, M., \& Berg, P. (2000). BESA (Version 5.0.4) [Computer software]. Munich: Megis.

Schupp, H. T., Cuthbert, B. N., Bradley, M. M., Cacioppo, J. T., Ito, T., \& LANG, P. J. (2000). Affective picture processing: The late positive potential is modulated by motivational relevance. Psychophysiology, 37, 257-261.

Schupp, H. T., Junghöfer, M., WeIKe, A. I., \& Hamm, A. O. (2003a). Attention and emotion: An ERP analysis of facilitated emotional stimulus processing. NeuroReport, 14, 1107-1110.

Schupp, H. T., Junghöfer, M., Weike, A. I., \& Hamm, A. O. (2003b). Emotional facilitation of sensory processing in the visual cortex. Psychological Science, 14, 7-13.

Schupp, H. T., JunghöFer, M., Weike, A. I., \& Hamm, A. O. (2004). The selective processing of briefly presented affective pictures: An ERP analysis. Psychophysiology, 41, 441-449.

Schupp, H. T., Öhman, A., Junghöfer, M., Weike, A. I., StockBURger, J., \& HAMm, A. O. (2004). The facilitated processing of threatening faces: An ERP analysis. Emotion, 4, 189-200.

Schupp, H. T., Stockburger, J., Codispoti, M., Junghöfer, M., Weike, A. I., \& Hamm, A. O. (2007). Selective visual attention to emotion. Journal of Neuroscience, 27, 1082-1089.

Schutter, D. J. L. G., De HaAn, E. H. F., \& van Honk, J. (2004). Functionally dissociated aspects in anterior and posterior electrocortical processing of facial threat. International Journal of Psychophysiology, 53, 29-36.

Schweinberger, S. R., Pickering, E. C., Jentzsch, I., Burton, A. M., \& KaUfmann, J. M. (2002). Event-related brain potential evidence for a response of inferior temporal cortex to familiar face repetitions. Cognitive Brain Research, 14, 398-409.

SEnIOR, C. (2003). Beauty in the brain of the beholder. Neuron, 38, 525-528.

TAlairach, J., \& Tournoux, P. (1988). Co-planar stereotaxic atlas of the human brain: 3-dimensional proportional system. An approach to cerebral imaging (M. Rayport, Trans). Stuttgart: Thieme.

Thornhill, R., \& Gangestad, S. W. (1999). Facial attractiveness. Trends in Cognitive Sciences, 3, 452-460.

Ullsperger, P., \& Grune, K. (1995). Processing of multi-dimensional stimuli: P300 component of the event-related brain potential during mental comparison of compound digits. Biological Psychology, 40, 17-31.

Vuilleumier, P., \& Driver, J. (2007). Modulation of visual processing by attention and emotion: Windows on causal interactions between human brain regions. Philosophical Transactions of the Royal Society B, 362, 837-855.

Werheid, K., Alpay, G., Jentzsch, I., \& Sommer, W. (2005). Priming emotional facial expressions as evidenced by event-related brain potentials. International Journal of Psychophysiology, 55, 209-219.

Werheid, K., Schacht, A., \& Sommer, W. (2007). Facial attractiveness modulates early and late event-related brain potentials. Biological Psychology, 76, 100-108.

Winston, J. S., O’Doherty, J., Kilner, J. M., Perrett, D. I., \& Dolan, R. J. (2007). Brain systems for assessing facial attractiveness. Neuropsychologia, 45, 195-206.

Zaidel, D. W., \& Deblieck, C. (2007). Attractiveness of natural faces compared to computer constructed perfectly symmetrical faces. International Journal of Neuroscience, 117, 423-431.

(Manuscript received November 21, 2006; revision accepted for publication December 18, 2007.) 